\title{
Experimental research on the effect of accelerated aging conditions on the performance of diesel lubricating oil
}

\author{
Zenghui Yin ${ }^{1,2, *}$ Enxing Zhang ${ }^{2}$, Jing $\mathrm{Hao}^{2}$, and Guotian $\mathrm{Li}^{2}$ \\ ${ }^{1}$ Tianjin University, China \\ ${ }^{2}$ China Automotive Technology and Research Center Co., Ltd., China
}

Keywords: accelerated aging, diesel lubricating oil, bench test, physical and chemical analysis, tribology.

\begin{abstract}
In this paper, a specific engine is selected to perform a bench test to evaluate the performance of the diesel lubricating oil. The injection time of the original engine is changed, and an appropriate after-injection strategy is selected to achieve accelerated aging of the lubricating oil.In the engine bench test, oil samples are taken at regular intervals to analyze the physical and chemical indicators and tribological characteristics, to determine the regularity of the change of the oil aging degree. At the same time, two different kinds of diesel lubricating oil were used for the test, so as to compare the performance parameters of different kinds of the lubricating oil during the aging process.
\end{abstract}

\section{Preface}

As the power of the car, the engine is the "heart" of it. Because the engine speed is large; the temperature is high and the torque fluctuates greatly in the running process. The internal combustion engine is developing towards high power and high torque. The temperature and pressure in the cylinder are increasing continuously, which leads to the worse working environment ${ }^{[1]}$. There are strict requirements for engine's use conditions, and the lubricating oil must meet the requirements of its work. The lubricating oil has the functions of lubrication, wear reduction, cooling, cleaning and sealing during engine operation ${ }^{[2]}$. As the lubricating oil ages, its viscosity, fluidity and heat dissipation decrease ${ }^{[4]}$. Studies have shown that the acidity and soot content of the lubricating oil increases after 15 hours of aging $^{[4]}$. The study also showed that the lubricating oil will reduce the rate of oil film formation after aging ${ }^{[5]}$. The friction pairs in the engine can not build a good oil film due to the aging lubricating oil and accelerated wear, which will reduce fuel economy ${ }^{[6]}$. In severe cases, it will cause accidents such as engine cylinder pulling. Therefore, it is of great significance to explore the changing trend of oil performance in aging process and analyze the changing trend of performance parameters of different grade lubricating oil in aging condition, to select the lubricating oil grade and oil change time.

\footnotetext{
* Corresponding author: zhangenxing@catarc.ac.cn
} 
Oil temperature, fuel oil, combustion products and so on will have an impact on oil aging. Hydrocarbons, oxides and soot generated from the combustion process of the diesel engine are mixed with the exhaust gas and enter the crankcase through the piston, piston ring and cylinder. Gas containing diesel, carbon dioxide, water vapor, sulfide, nitrogen oxides, and oxides are mixed with the lubricating oil, resulting in poor performance of the lubricating oil. By increasing the injection delay angle, a greater degree of incomplete combustion of the fuel is achieved and the aging speed of the lubricating oil is accelerated. A large amount of soot is generated in a short time to simulate the normal aging process of the lubricating oil and explore the physicochemical properties of the lubricating oil to explore the variation law of the physical and chemical characteristics of lubricating oil.

As a result, the soot content in the lubricating oil reaches a certain value, which will cause the oil film to break up in the process of friction, and lead to the increase of friction coefficient and wear rise ${ }^{[7]}$. Therefore, it is necessary to understand the change of friction characteristics during the oil aging. The wear spot diameter and friction coefficient are important indexes to evaluate oil friction characteristics. Four-ball testing machine, ring-block testing machine, ball-disk testing machine and Fallex $\mathrm{V}$ block testing machine are usually used to evaluate tribological performance. Compared with the others, the four-ball friction test machine can simulate the industrial friction pair by changing the friction pair and adjusting the control parameters. It is commonly used in the screening and evaluation of lubricants ${ }^{[8]}$. In addition, the four-ball test machine can realize the actual working conditions in the simulation test, and it is the first choice for evaluating the lubricanting oil in the world. So this paper uses four-ball testing machine to test the tribological characteristics of the lubricanting oil.

In this paper, we simulated the normal oil aging process by increasing the fuel injection angle and accelerating the generation of soot. The physical and chemical indicators and wear characteristics of the two oils A and B were analyzed, and the change law of oil performance with the aging process was studied.

\section{Introduction of the test}

A Weichai WP13 engine is used as a testing machine to simulate the running and aging of the lubricating oil in the engine. The test condition was selected as $1800 \mathrm{r} / \mathrm{min}$ at $100 \%$ load. The specific parameters of the engine are shown in Table 1 . Because the original machine had a slow soot growth rate when the fuel injection time is the $7^{\circ} \mathrm{CA} \mathrm{BTDC}\left(+7^{\circ} \mathrm{CA}\right)$. So from $1^{\circ} \mathrm{CA}$ BTDC $\left(+1^{\circ} \mathrm{CA}\right), 1^{\circ} \mathrm{CA}$ ATDC $\left(-1^{\circ} \mathrm{CA}\right), 3^{\circ} \mathrm{CA}$ ATDC $\left(-3^{\circ} \mathrm{CA}\right), 5^{\circ} \mathrm{CA}$ ATDC $\left(-5^{\circ} \mathrm{CA}\right)$, we select an optimal after-injection angle among multiple after-injection injection angles to accelerate the soot generation and simulate the rapid aging process of the engine. This paper selects CJ-4 and CI-4 diesel lubricating oil to carry on the test. The engine is operated for a certain period of time with an appropriate after-injection angle, and oil samples are taken per 5 hours for physical and chemical indicators and tribological analysis. We analyze the impact of accelerated old chemical conditions on the performance of different grades of diesel lubricating oil.

Table 1. WP13 Weichai Engine parameters

\begin{tabular}{cc}
\hline Parameters/units & Parameters \\
\hline Air intake form & Supercharged Medium Cold \\
Number of cylinders & 6 \\
Cylinder alignment & Direct \\
Emission standards & National V emission standard \\
Emission control mode & Electronic High Voltage Common + SCR \\
Bore $\times$ stroke $/$ mm & $127 \times 165$ \\
Total piston displacement/ & 12.54
\end{tabular}




\section{Selection of after-injection angles}

\subsection{Original emission characteristics}

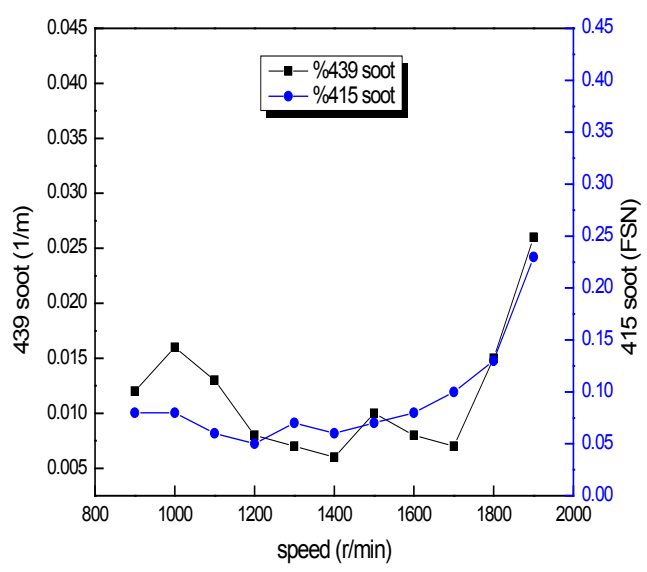

Fig. 1. Selection of external characteristic soot value.

As shown in Figure 1, the test uses AVL 439 opaque soot and AVL415 filter paper soot for comparison. The measured values of the two instruments are close and have a consistent trend. For convenience of comparison, AVL 439 soot meter is used uniformly in subsequent measurements. The value of the original soot emission of the engine is 0.015 $1 / \mathrm{m}$ (at $1800 \mathrm{r} / \mathrm{min}$ ), which is not enough to generate more soot content to achieve accelerated aging diesel lubricating oil. So this paper uses the delayed fuel injection strategy to accelerate the soot generation, and the after-injection angles are selected as $+1^{\circ} \mathrm{CA},-1^{\circ} \mathrm{CA},-3^{\circ} \mathrm{CA}$ and $-5^{\circ} \mathrm{CA}$.

\subsection{Effect of soot growth rate at diffrerne injection strategies}




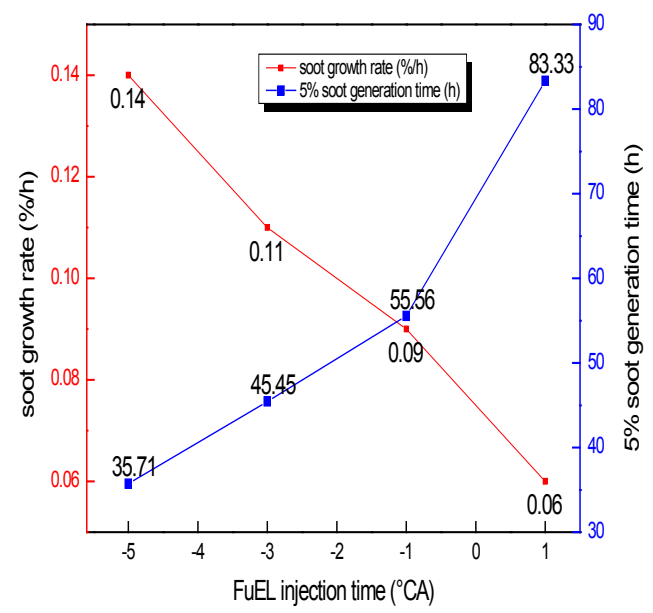

Fig. 2. Soot growth rate under different injection strategies.

The soot is a mixture of various substances produced by incomplete combustion of fuel during engine operation. It is dissolved in oil in solid state ${ }^{[9]}$, which leads to the decrease of oil performance and the aggravation of engine wear. With the continuous delay of the after-injection angle, it can be seen from figure 2 that the rate of soot production is increasing, and the rate of soot growth is gradually increasing from $0.06 \% / \mathrm{h}$ at $+1{ }^{\circ} \mathrm{CA}$ to $0.14 \% / \mathrm{h}$ at $-5^{\circ} \mathrm{CA}$. So the corresponding time required to achieve the target of $5 \%$ soot content is also reduced from $83.33 \mathrm{~h}$ at $+1^{\circ} \mathrm{CA}$ to $35.71 \mathrm{~h}$. at $-5^{\circ} \mathrm{CA}$.

\subsection{Effect of diffrerne injection strategies on engine heat load}

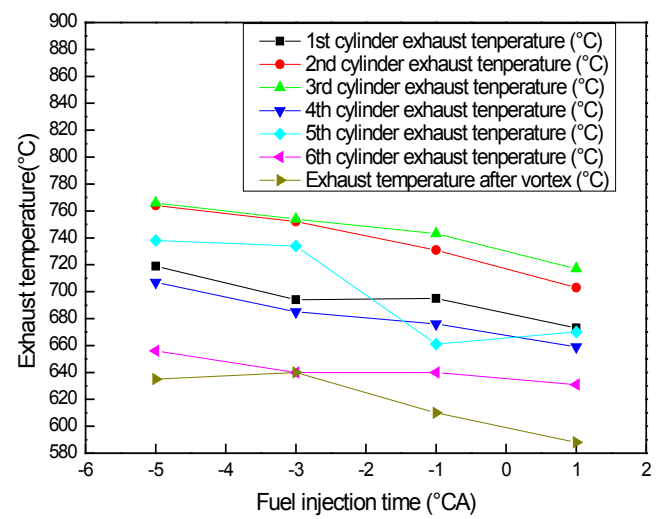

Fig. 3. Exhaust temperature for different injection strategies.

As can be seen from Figure 3, the effect of different after-injection angles on the exhaust temperature is different. With the continuous delay of the after-injection angle, the exhaust temperature of the six cylinders and post-vortex temperature increases. When the after-injection angle is $-5^{\circ} \mathrm{CA}$, the temperature after vortex can even reach $640^{\circ} \mathrm{C}$, and the temperature in each cylinder is more than $700^{\circ} \mathrm{C}$. This is due to the larger angle of the 
after-injection, the amount of fuel in the cylinder incompletely burned increased. More fuel in the exhaust manifold continue to burn resulting in higher temperature. Excessively high temperature will cause the engine high thermal load, and poor running stability is prone to various failures. To ensure the stable operation of the test and the rapid generation of the soot, the fuel injection angle of $1^{\circ} \mathrm{CA}$ BTDC $\left(+1^{\circ} \mathrm{CA}\right)$ is selected for the test, and the temperature after vortex is about $590^{\circ} \mathrm{C}$, the maximum temperature of 6 cylinders is $720^{\circ} \mathrm{C}$.

\section{Comparative analysis of physical and chemical indexes of diesel lubricating oil}

\subsection{Comparison of soot content}

The oil A and oil B selected in this test are diesel lubricating oil of $15 \mathrm{~W}-40$ viscosity of CJ-4 grade and CI-4 grade, to compare the performance of the lubricating oil in the condition of high soot under the accelerated aging conditions. As shown in Figure 4, the engine with a after-injection angle of $-1{ }^{\circ} \mathrm{CA}$ runs at $1800 \mathrm{r} / \mathrm{min}$ for 100 hours, The soot growth of the two types oils in this case is basically the same, maintaining a good reproducibility of results. When operating to 100 hours, the soot content of the two types oils can reach $5 \%$, which is equivalent to the normal operation of the engine at full load for more than 2500 hours, and the accelerated aging effect is obvious.

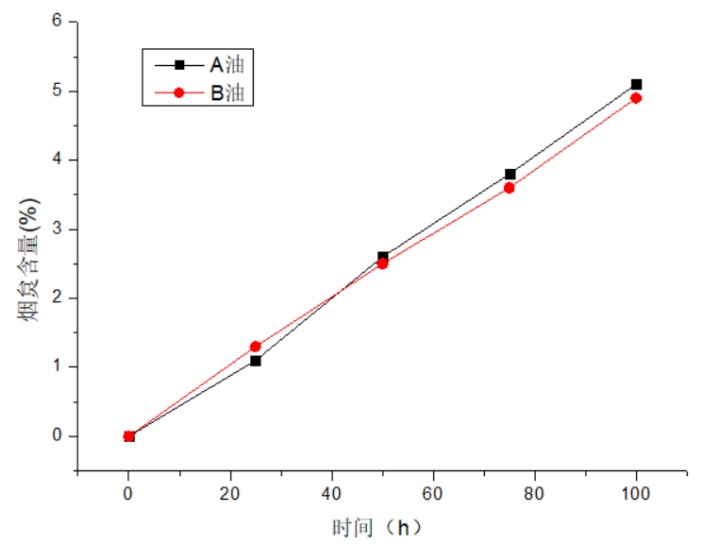

Fig. 4. Soot content changes of oil A and oil B.

\subsection{Comparison of kinematic viscosity}




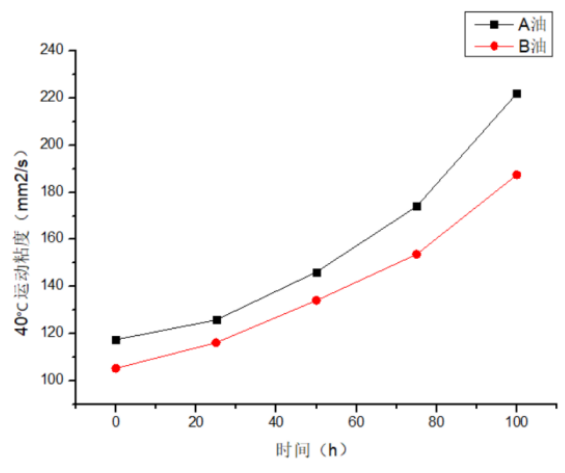

Fig. 5. Kinematic viscosity comparison of oil A and oil $\mathrm{B}$ at $40^{\circ} \mathrm{C}$.

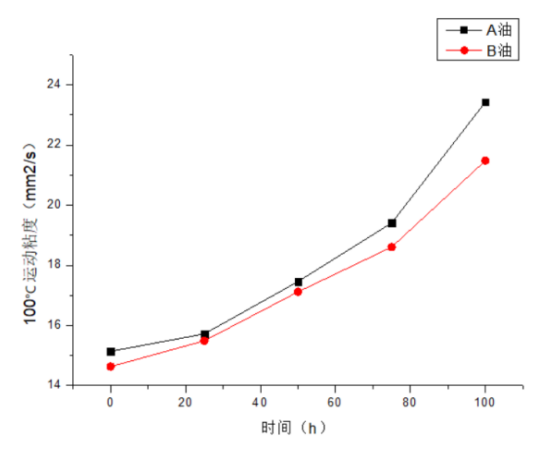

Fig. 6. Kinematic viscosity comparison of oil A and oil $\mathrm{B}$ at $100^{\circ} \mathrm{C}$

As can be seen from figures 5 and 6, oil A and oil B under accelerated aging conditions, $40^{\circ} \mathrm{C}$ kinematic viscosity and $100^{\circ} \mathrm{C}$ kinematic viscosity showed a significant increase, And as time goes by, the difference between the two types oils is increasing. Because both types oils are diesel lubricating oils of $15 \mathrm{~W}-40$ viscosity grade. Therefore, at the initial stage, the kinematic viscosity of both types oils at $100^{\circ} \mathrm{C}$ is around $15 \mathrm{~mm}^{2} / \mathrm{s}$. With the aging of the lubricating oil, the viscosity of oil A increases significantly faster than that of oil B. At 100 hours, the viscosity of oil A is $23.43 \mathrm{~mm}^{2} / \mathrm{s}$; the viscosity of s,B oil is 21.48 $\mathrm{mm}^{2} / \mathrm{s}$. The difference between the two is very obvious. The accelerated aging method makes more accurate judgments on the viscosity changes of different lubricating oils during the aging process, which can help judge the quality of the lubricating oils.

\subsection{PH comparison}

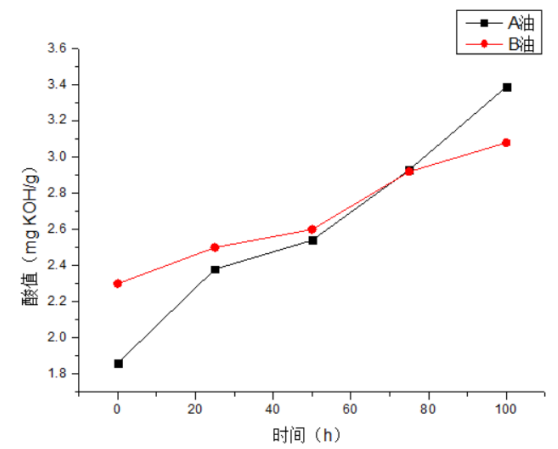

Fig. 7. Comparison of acid value of oil A and oil B.

From figure 7, we can see that the acid value of oil $\mathrm{A}$ and oil $\mathrm{B}$ increases with the time. The acid value of oil A increased from $1.86 \mathrm{mgKOH} / \mathrm{g}$ to $3.89 \mathrm{mgKOH} / \mathrm{g}$, the acid value of oil B increased from $2.3 \mathrm{mgKOH} / \mathrm{g}$ to $3.08 \mathrm{mgKOH} / \mathrm{g}$. The early acid value of oil $\mathrm{A}$ is lower than that of oil $\mathrm{B}$, but with the accelerated aging of the lubricating oil, its growth rate 
is significantly faster than that of oil B. The acid value of oil A at 100 hours is significantly higher than that of oil B. Excessively rapid increase in acid value will affect the quality of the lubricating oil, accelerate the wear of engine parts, and affect the normal operation of the engine.

The base value of oil A is obviously higher than that of oil B, and with the accelerated aging of the lubricating oil the base value of oil A shows a linear downward trend, from the initial $8.16 \mathrm{mgKOH} / \mathrm{g}$ to $6.33 \mathrm{mgKOH} / \mathrm{g}$. But oil $\mathrm{B}$ had no obvious change. This shows that oil A has better anti-oxidation performance. During the aging process of the lubricating oil, it reacts with sulfur-containing acidic substances in the fuel, weakens the acidic substances to the engine's corrosion, and cleans the acidic substances adhered on the surface of each friction pair, which is dissolved in lubricating oil. So it can prolong the life of the lubricating oil.

\subsection{Iron comparison}

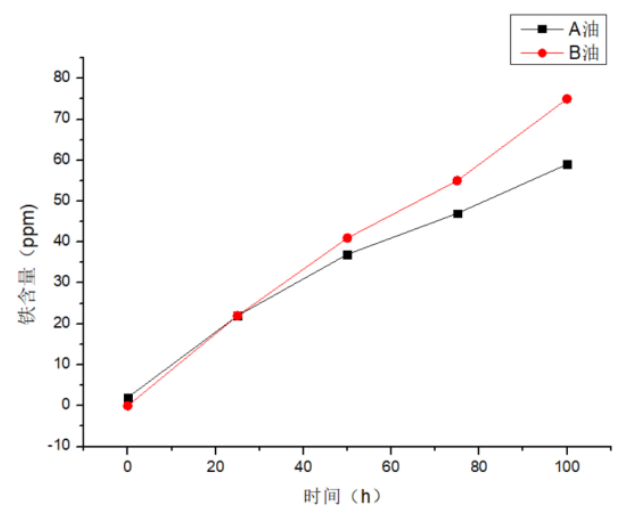

Fig. 9. Comparison of oil A and oil B iron content.

The main material of the engine friction pair is cast iron, and the friction in the running engine will lead to a certain content of iron dissolved in the oil. Figure 9 shows that the friction between oil $\mathrm{A}$ and oil $\mathrm{B}$ becomes worse with the accelerated aging of the lubricating oil. Compared with oil A, the lubricating performance of oil B is basically consistent in the first 20 hours, and the content of iron is relatively close. After 20 hours, the degree of friction of oil B is worse than that of oil A. The speed of the increase in iron is significantly higher than that of oil A. The difference between the two increases sharply with aging progress. The content of iron in oil B reaches $75 \mathrm{ppm}$ by $100 \mathrm{~h}$, while it in oil A is $59 \mathrm{ppm}$.

\section{Comparison of tribological characteristics of diesel lubricating oil}

The test used a four-ball friction test machine to test the tribological characteristics of oil A and oil B. The four-ball machine was set at $1200 \mathrm{r} / \mathrm{min}, 40 \mathrm{~N}$, and $100^{\circ} \mathrm{C}$. The friction diameter and coefficient of friction were measured separately to clarify the change trend of the wear resistance and wear reduction of two oils under the aging of the lubricating oil.

\subsection{Diameter of wear spots}




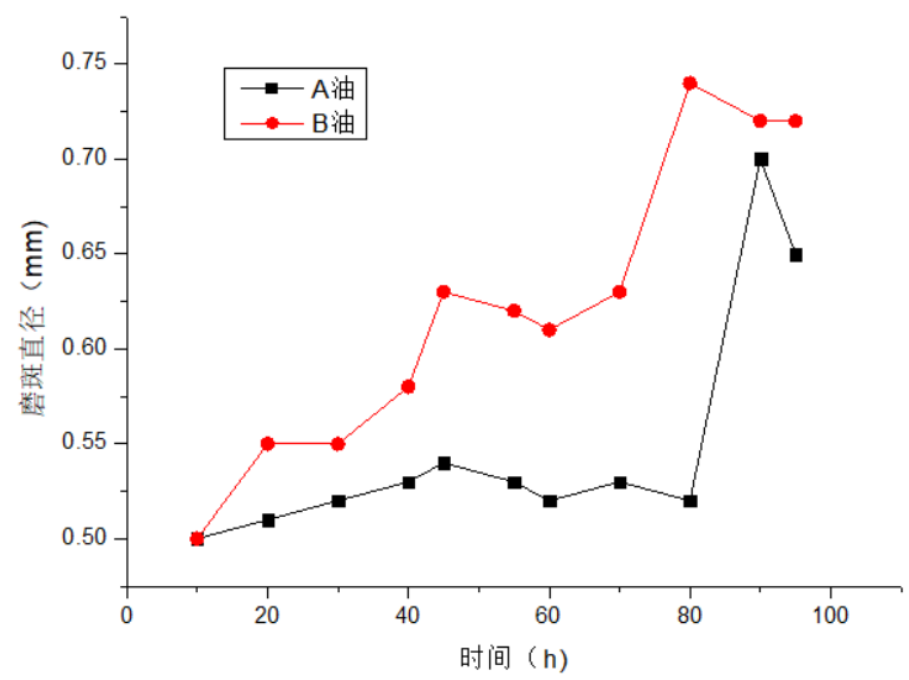

Fig. 10. Comparison of oil A and oil B in the diameter of wear spots.

With the continuous aging of lubricating oil, the wear spot diameters of oil A and oil B continue to increase with time. When the soot content is too high and the oil film cannot be completely covered, the wear spot diameter increases sharply. Fig.10 shows that wear spot diameter of oil A increased at a slower rate in the first 40 hours, and the increase in soot content from $45 \mathrm{~h}$ to $80 \mathrm{~h}$ had no significant effect on the wear spot diameter. After 80 hours, the soot content reached $4.1 \%$ and the oil film could not be completely covered, so the diameter of the wear spot began to rise sharply. The change trend of wear spot diameter of oil B in the first 70 hours is similar to that of oil A. The growth rate of wear spot diameter is higher than that of oil A. After 70 hours, the soot content reached 3.0\% and the oil film could not be completely covered, so the diameter of the wear spot began to increase sharply. The wear resistance of both oils can be well characterized by the change trend of the wear spot diameter. Oil A is obviously better than oil B in wear resistance.

\subsection{Friction factor}

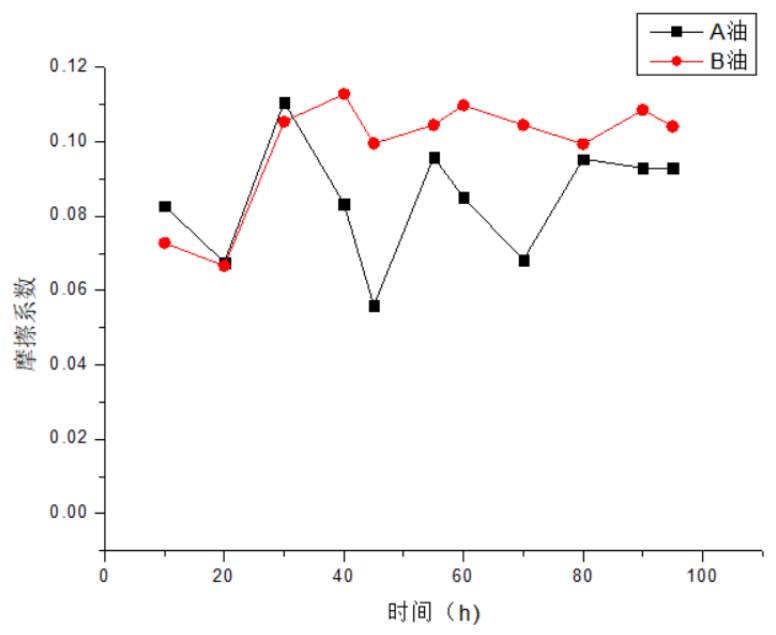


Fig.. 11. Comparison of oil A and oil B in friction coefficient.

Using a four-ball experimental machine, the friction coefficient in the wear process for one hour is averaged. The results are shown in Figure 11. The friction coefficient of oil A and oil $\mathrm{B}$ in the first 30 hours has a certain upward trend, but there is no obvious difference between the two. With time, oil A shows a tendency to decrease in volatility while oil B slightly increased. The friction coefficient of oil A and oil B is relatively stable after 80 hours, and the friction coefficient of oil B is obviously higher than that of oil A. The friction-reducing properties of two oil samples have once again been more clearly compared.

\section{Conclusions}

In summary, this paper compares the soot generation and the temperature after the vortex and in the cylinder rate at different injection angles. Under the accelerated aging conditions, the physical and chemical indicators and tribological characteristics of the oil A and oil B were compared. Came to the following conclusions:

1. The comparison of various after-injection strategies shows that $1^{\circ} \mathrm{CA} \mathrm{BTDC}\left(+1^{\circ} \mathrm{CA}\right)$ can satisfy the rapid generation of soot and ensure the engine to run in the lower heat load. Ensure that diesel oil can run at $1800 \mathrm{r} / \mathrm{min}$ for 100 hours to simulate the normal operation of the process of oil aging, to achieve accelerated oil aging.

2. Comparing two different grades of diesel lubricating oil in accelerated aging progress, under the condition that the soot content increases samely in 100 hours, the physicochemical parameters of $40^{\circ} \mathrm{C}$ kinematic viscosity, $100^{\circ} \mathrm{C}$ kinematic viscosity, $\mathrm{pH}$ value and iron are analyzed. In the process of oil aging, the performance parameters accelerate deterioration synchronously, which can simulate the actual aging of the lubricating oil. In this process, the deterioration degree of different grades of the lubricating oils is compared to clarify the difference in the aging speed of different grades of the lubricating oils.

3. The tribological characteristics of the accelerated aging diesel lubricating oil were studied. The four-ball friction test machine was used to measure the wear spot diameter and friction coefficient of the lubricating oil in the accelerated aging progress. It has a clear understanding of the changes in the degree of wear reduction and wear resistance of lubricating oil aging, and made a comparative study on the wear resistance and wear reduction of different grades of the lubricating oil.

\section{References}

1. Anon. The next generation of high performance synthetic oils[J]. Fules \& lubes International, 1995:10.

2. JunjieJ Yang. Grease and additives [M].] Petroleum Industry Press, 2011.

3. Mrinmoy D,John N and Gregory J.T.et al."Effects of Oil Aging on Laboratory Measurement of Emissions from a Legacy Heavy-duty Disel Engine," SAE Technical Paper 2011-01-1163,2011, dio: 10.4.271/1011-01-1163.

4. Huiming Wang Analysis of oxidation factors and oxidation resistance of internal combustion engine lubricating oil[J]. Automotive Engine, 1992.

5. Gangopadhyay, A., Liu, Z., Simko, S., Lam, W.et al.,"The Effect of Friction Modifiers and DI Package on Friction Reduction Potential of Next Generation Engine Oils: Part II Aged Oils," SAE Technical Paper 2019-01-0303, 2019, doi: 10.4271/2019-01-0303. 
6. Simth T R, Kersey V , Bidwell T . The Effect of Engine Age, Engine Oil Age and Drain Interval on Vehicle Tailpipe Emissions and Fuel Efficiency[C]// Sae International Fall Fuels \& Lubricants Meeting \& Exhibition. 2001.

7. PengSu, Yun Xiong, Xiao Liu, He Yang. Characterization and tribological properties of diesel engine soot [J].] Journal of Tribology ,2017,37(01):83-89.

8. Botian Liu, Hong Gao, Hui Zhou, et al. Application of Four Ball Testing Machine in Evaluation of Liquid Lubricant [J].] Physical and chemical tests (physical fascicles),2015,51(11):795-798,826

9. Gang Zhao Xinlu Feng, Qi He. Harm and detection methods of soot in diesel engine lubricants [J]. Metrology and Testing Technology, 2006(03): 14-16. 